\title{
Lugares da participação e formação da cidadania
}

\author{
Danilo Romeu Streck \\ Telmo Adams*
}

\section{O tema e seu entorno}

A presente reflexão parte do pressuposto de que a participação e o controle social são condição para a conquista e a garantia de outros direitos como saúde, alimentação, trabalho, moradia, educação e transporte. Democracia, como entendida aqui, é antes de tudo uma forma de vida da qual a escolha dos governantes é uma conseqüência. Por isso, o cumprimento da formalidade jurídica jamais eximirá o povo no seu conjunto e cada cidadão e cidadã em particular da responsabilidade para com o conjunto da sociedade, e os ocupantes de cargos públicos de conceber o seu trabalho a serviço da coletividade.

* Danil R. Streck é doutor em Educação, professor do PPG em Educação da Unsinos; mail: dstreck@unisinos.br. Telmo Adams é mestre em Serviço Social e doutorando em Educação na Unisinos, bolsista da Capes; mail: smada@cpovo.net. O artigo é resultado parcial do projeto de pesquisa Processos sociais emancipatórios na América Latina como mediação pedagógica para a constituição do público, que conta com apoio do CNPq. Participam do projeto as bolsistas de iniciação científica: Vanice Wentz (CNPq), Mônica Kley (Fapergs), Jaqueline dos Santos (Probic/Fapergs) e Rita de Cássia Machado (Unisinos).

\begin{tabular}{|l|l|l|l|l|l|}
\hline Civitas & Porto Alegre & v. 6 & n. 1 & jan.-jun. 2006 & p. 95-117 \\
\hline
\end{tabular}


O olhar estará focado no que aqui serão denominados os lugares e instâncias da participação, com destaque aos conselhos gestores de políticas públicas. A hipótese, como ponto de partida, é que existe uma forte tendência de a participação ser sugada no labirinto dos canais de participação que não se comunicam e nos quais muitas vezes não se vê a saída em termos de resultados. A análise dos lugares no seu conjunto poderá evidenciar limites e possibilidades de cada um deles e contribuir para a formação de uma cidadania ativa.

Na década de 1960 Paulo Freire cunhou a expressão cultura do silêncio para designar a secular exclusão política da maioria o povo brasileiro. A história está repleta de vozes abafadas e de vidas sacrificadas em nome da fé, da ordem, do progresso e, mais recentemente, da governabilidade, da sustentatibilidade ou da competitividade. Ler o mundo e dizer a sua palavra são, para este educador, processos concomitantes à aprendizagem do alfabeto. A humanização passa pela possibilidade de sentir-se construtor do destino coletivo do povo a que se pertence.

Recente estudo do Pnud sobre a democracia na América Latina revela que pouco mais da metade da população $(51,8 \%)$ foram socializadas sob regimes ditatoriais (Pnud, 2004, p. 139). Este mesmo estudo indica que mais da metade dos cidadãos estariam dispostos a trocar a democracia por um sistema socioeconômico mais eficiente. Ou seja, por baixo do verniz da institucionalidade democrática se esconde a possibilidade da irrupção do autoritarismo, uma situação sobejamente aproveitada por lideranças de diferentes matizes ideológicos.

Os regimes autoritários, no entanto, geraram as suas próprias contradições e foi no período das ditaduras militares que cresceram as lutas populares, cujas conquistas, em nosso país, foram ao menos parcialmente incorporadas na Constituição Federal de 1988. Olhando o mapa mundial, pode-se verificar que a democracia se firmou, nas últimas décadas, como o sistema político consensuadamente mais adequado para a organização da sociedade e para o desenvolvimento humano. O mapa político (Barnett e Low, 2004; Baquero, 2000, p. 17) indica hoje poucas regiões ou países que não se assumem como democracias. Amartia Sen classificou, por isso, a emergência da democracia como o fato mais significativo do século XX. (apud Jones, 2004, p. 161). 
O outro lado do mesmo fenômeno é, paradoxalmente, o declínio da cidadania. Expressões como "democracia de baixa intensidade" tornaram-se comuns para caracterizar a falta de qualidade da cidadania. Corre-se hoje o risco de ter democracias sem cidadania. As denúncias da ausência dos cidadãos na vida pública e as tentativas de conectá-los à sua polis vêm de todos os cantos do mundo. No front mais amplo, escreve Tony Wright (1996, p. 11), "as perspectivas podem parecer bastante desanimadoras. Nós não precisamos assumir toda a atual moda retórica sobre globalismo para saber que o mundo contemporâneo parece um lugar sem muita esperança se o objetivo é remodelar os instrumentos de autogoverno coletivo". Sua constatação, logo adiante, corresponde à experiência de vida da grande maioria dos cidadãos e cidadãs: "É um mundo que nos convida a refugiar-nos numa ideologia da sobrevivência pessoal, ou de surfar num ciberespaço de democracia virtual e pessoal" (idem).

Não é de estranhar que nesse contexto ressurja o interesse pela democracia participativa. A crítica à democracia representativa liberal, que se tornou hegemônica, ${ }^{1}$ é que ela não percebe a participação do cidadão e da cidadã como um valor em si mesmo. A delegação da tarefa de governar a representantes para atender aos interesses da população até a próxima eleição mostra, de fato, as suas fraquezas e limitações. O pressuposto central da teoria participacionista é que cada pessoa tem a capacidade de desenvolver não apenas o seu self, mas de expandir este auto-interesse para abranger uma identificação e um comprometimento com o bem-estar dos outros (Bachrach e Botwinick, 1992, p. 20).

Levar a sério o contexto estrutural global é um imperativo para evitar visões simplificadas ou meramente instrumentalizadas da participação. $\mathrm{O}$ alerta de um analista colombiano serve muito bem para a realidade brasileira: “A participação da população nos assuntos locais opera como um lenitivo político da crescente exclusão econômica gerada pela globalização do capital" (Restrepo, 1997, p. 32). Contraditoriamente, afirma ele, na Colômbia, as idéias de descentralização e participação começam a gestar-se no início dos

\footnotetext{
"Vale a pena, portanto, perceber que a primeira via de afimação da concepção hegemônica de democracia no pós-guerra é uma via que leva do pluralismo valorativo à redução da soberania e, em seguida, à passagem de uma discussão ampla sobre as regras do jogo democrático à identificação da democracia com as regras do processo eleitoral” (Santos, 2003, p. 45).
} 
anos 1970, quando a economia se internacionaliza e quando em nome dos ajustes se precisa colocar um freio à crescente articulação dos movimentos cívicos, dando origem ao que ele denomina de participação tutelada.

O movimento da sociedade, no entanto, não se deixa encapsular em concepções únicas. Seria impossível negar que as prerrogativas e exigências de participação contidas na constituição brasileira de 1988 são uma conquista principalmente - da sociedade civil organizada. Para a Constituinte confluíram as lutas pelo acesso à terra, pela moradia, pela saúde, pela educação, entre tantas outras e o resultado é uma moldura legal que permite um amplo espaço para a movimentação democrática de governados e governantes, e entre eles.

É esta moldura, por exemplo, que permite a construção de uma experiência inédita, ao menos com este grau de radicalidade, como o Orçamento Participativo que tem um marco na gestão de Porto Alegre, desde 1989. Seu ineditismo está em chamar a participação do povo naquilo que pode ser considerado o núcleo duro (Fedozzi, 1999, p. 107) do planejamento, ou seja, o seu orçamento. Há muito pouco de original, por exemplo, em chamar os pais para colaborarem na reforma da escola, seja com doação de recursos ou com mão de obra. Ou no fato de uma prefeitura mobilizar a comunidade para "trazer" determinada indústria. O que despertou a atenção internacional no Orçamento Participativo foi a convicção de que o povo sabe melhor que os governantes quais são as suas prioridades e que por isso ele tem o direito de participar em sua identificação, na alocação dos recursos e no acompanhamento da execução dos projetos.

Experiências como essas se repetem em muitos lugares no país e no mundo. Boaventura de Sousa Santos (2003) e sua equipe de pesquisa coletaram e analisaram várias dessas experiências no mundo ${ }^{2}$ e propõem que nelas se encontram as sementes de uma teoria contra-hegemônica de democracia que questiona "uma gramática social e estatal de exclusão" (Idem, p. 57), propondo uma outra mais inclusiva. Hoje o Fórum Social Mundial se apresenta como o grande catalisador de sonhos e de projetos de um democracia substantiva, ao mesmo tempo mais igualitária e mais respeitosa das diferenças.

2 São analisadas experiências de democracia participativa na Índia, na África do Sul, na Colômbia, no Brasil e em Portugal. 


\section{Compreensões de participação e controle social}

A participação tende a se tornar uma panacéia para os males da sociedade, legitimando as ações à esquerda e à direita do espectro político e não raro encobrindo a crise de legitimidade que afeta os governos. Cabem, por isso, algumas considerações sobre o sentido ou os sentidos que se atribuem ao conceito nesse estudo. Não se trata de procurar resgatar algum sentido original ou verdadeiro, mas sobretudo de chamar atenção para o fato de que o campo semântico faz parte das disputas de infuência e de poder.

Se hoje o conceito é associado com democracia, nem sempre foi assim. Conforme Carole Pateman, na segunda metade do século passado, devido à recente história do fascismo e depois o estabelecimento de regimes totalitários com altas taxas de participação das massas, o conceito passou a ser mais associado com totalitarismo do que com democracia. Daí a pergunta que muitos cientistas políticos começaram a fazer sobre a viabilidade de democracias conforme as teorias liberais clássicas. "A conclusão esboçada [...] é a de que a visão clássica do homem democrático constitui uma ilusão sem fundamento e que um aumento de participação política dos atuais não participantes poderia abalar a estabilidade do sistema democrático" (Pateman, 1992, p. 11). No caso da América Latina o estabelecimento das ditaduras confirma parte desta suspeita. Mas, como veremos adiante, há outro lado deste mesmo fato.

Já em Rousseau, considerado pelos cientistas políticos um dos teóricos fundacionais da participação, há uma ambigüidade fundamental quanto às possibilidades da participação. Por um lado, ele reconhece no seu Contrato Social que "quando alguém disser dos negócios do estado: Que me importa? pode-se estar certo de que o estado está perdido" (Rousseau, 1983, p. 107). No mesmo livro ele dirá que a democracia, como o regime ideal, não é para homens e sim para deuses. Como não somos deuses temos que nos satisfazer com algo menos perfeito (idem, p. 86).

Isso apenas mostra como o contrato social moderno foi de abrangência limitada. As mulheres reclamam, com razão, que elas ficaram de fora. ${ }^{3}$ Para os negros foi um contrato entre homens brancos que, enquanto afirmavam a igual-

3 Este tema é elaborado no capítulo 2 do livro Educação para um novo contrato social, tendo por base, respectivamente as análises de Carole Pateman ( $O$ contrato sexual), Charles Mills (O contrato racial) e Michel Serres (O contrato natural). 
dade de todos os homens (sic!), promoviam o tráfico de escravos da África. Por fim, foi também um contrato que separou o ser humano da natureza, transformando-a em mero suporte para a realização humana.

Essas limitações, no entanto, não são suficientes para negar o valor da participação. Quem sabe, por isso, devêssemos associá-la com uma visão utópica de organização social e de gestão da coisa pública, como sugerem Benello e Roussopoulos (1971, p. 280):

Talvez seja necessário ver a democracia participativa como uma utopia, no sentido de que ela não é completamente realizável, dadas as várias limitações sociológicas e psicológicas, mas em vez disso realizável apenas em passos, e certamente valiosa como instrumento para lidar com problemas como educação, democracia industrial, organizar os pobres, e dar ao povo uma estratégia para autodeterminação.

As teorias e as práticas de participação compartilham com Rousseau pelo menos alguns traços de sua antropologia otimista. Aposta-se na capacidade humana de escolher, de decidir e de ser solidário. Leonardo Boff argumenta que a participação é um fenômeno ou processo constitutivo da condição humana, que tem a ver fundamentalmente com a dignidade de mulheres e de homens. Conforme Boff (2000, p. 80), "pelo fato de ser pessoa, de ser criativo, livre, responsável, o ser humano vem dotado de uma vontade ontológica de participação. Não se trata de uma veleidade que pode ser ou não ser. Essa vontade é intrínseca". As formas dessa participação obviamente são cultural e historicamente condicionadas.

Podemos constatar que o liberalismo contribuiu na construção da idéia de uma cidadania universal, mas ele mesmo a reduziu a um status meramente legal. Direitos são iguais apenas na lei. Cooperação social é entendida como meio para chegar à prosperidade individual. A idéia de participação política para além do voto é estranha ao pensamento liberal, para o qual participação política e liberdade individual são incompatíveis.

Já a visão republicana enfatiza o valor da participação política, onde a inserção do indivíduo numa comunidade política tem um papel central. Participação política e liberdade individual não são somente compatíveis, mas a primeira é condição necessária para realizar a segunda. A participação cidadã 
depende da consolidação da esfera pública ${ }^{4}$ onde os indivíduos podem agir coletivamente sobre questões que afetam a população. Em decorrência, podese concluir que a participação cidadã é essencial para constituir uma identidade política baseada em valores de solidariedade, autonomia e reconhecimento da diferença.

Margarita Bonamusa (1997, p. 75-78) em seu estudo "Qué és la sociedad civil? Una mirada desde la Colombia" concluiu que há três maneiras de como diversos atores entendem o fortalecimento da sociedade civil. Uma primeira compreensão coloca-se na perspectiva sociocêntrica. O fortalecimento da sociedad civil seria um processo auto-referenciado, centrado na sociedade civil entendida como lugar da realização da democracia e do surgimento das alternativas de desenvolvimento. Enfatiza a sociedade civil permeada pelas classes sociais a partir do foco dos pobres organizados e dos setores populares ou daqueles que apóiam a organização popular. Privilegia o eixo socioeconômico e a primazia da comunidade sobre o estado. Uma segunda comprensão assume a perspectiva estadocêntrica ou neocorporativista. Esta tendência promove o fortalecimento da sociedade na relação direta com o estado. $\mathrm{O}$ ator principal do espaço público acaba sendo o representante do estado, sobre o qual a sociedade procura influir para direcionar a política em função dos seus interesses. Essa perspectiva enfatiza a capacidade de gerar interlocução especializada com o governo, onde as organizações têm em vista obter recursos para melhorar sua sustentabilidade financeira. E em terceiro lugar Bonamusa reconhece a perspectiva do público. Esta relaciona o fortalecimento da sociedade civil com o fortalecimento do público, que não se identifica com o estatal. As organizações da sociedade se vinculam à dimensão pública, da defesa dos interesses públicos e de gestão social que visa o interesse coletivo e o bem comum. Prevê a interação das organizações com o estado em espaços de participação. Assim, o público se coloca como uma mediação transparente entre a sociedade e o estado, onde o social e o político deixam de ser esferas separadas.

4 Na tradição de Habermas, a esfera pública constitui-se em espaço de formação da vontade coletiva, de debate público, de embate dos diversos atores da sociedade. De acordo com Vieira Lizst (2005, texto disponível na internet), "a esfera pública é o local de disputa entre os princípios divergentes de organização da sociabilidade. Os movimentos sociais constituem os atores que reagem à reificação e burocratização. Eles disputam com o Estado e com o mercado a preservação de um espaço autônomo e democrático de organização, reprodução da cultura e formação de identidade e solidariedade". 
É nessa linha que podemos afirmar a (re)construção do espaço público democrático com caráter emancipatório, em vista do primado da comunidade e da solidariedade e da autonomia da sociedade civil dos controles do estado e das imposições econômicas do mercado. Por isso, a esfera pública é a instância geradora de decisões coletivas, afirmando a democracia na institucionalização de consensos construídos em relação aos diferentes interesses.

Verificando as discussões sobre teorias participacionistas que tenham um horizonte de emancipação, alguns temas recorrentes ajudam a compor o quadro do tipo de participação a que este estudo se refere:

a) A participação constitui um valor intrínseco: Apenas uma visão estreita de democracia considera a participação um simples meio para atingir determinado fim. Ela é um bem em si mesma por propiciar condições para a realização do indivíduo e da coletividade.

b) Há um vínculo entre participação e igualdade: Experiências do Orçamento Participativo têm demonstrado que este pode ser um importante instrumento de inversão de prioridades para a aplicação de recursos públi$\cos$.

c) A participação engendra e nutre a identidade de grupos e movimentos: Através da participação são criadas e recriadas identidades que favorecem o desenvolvimento da auto-estima, seja de pessoas que lutam pela terra, das mulheres, dos jovens ou dos negros.

d) Há uma relação positiva entre participação e eficiência: As modernas teorias de gestão apostam na participação simplesmente porque o envolvimento efetivo e afetivo da pessoa acaba se traduzindo em resultados positivos.

e) A participação tem um valor pedagógico: Desde Rousseau, a participação tem a ver com a formação para a cidadania. Uma democracia tem como pressuposto cidadãos com um razoável grau de informação e capacidade de discernimento para poderem fazer parte da comunidade argumentativa. 
f) A participação favorece o surgimento de novas lideranças: Um dos desafios para a democracia é o surgimento de novas lideranças políticas. Experiências participativas são um espaço privilegiado para o desenvolvimento de líderes comprometidos com o contexto de onde emergem e com novas perspectivas em relação ao exercício do poder. ${ }^{5}$

g) Participação não pode ser delegada nem institucionalizada: A participação instaura um saudável tensionamento entre o instituído e o instituinte. Há uma permanente vigilância das relações objetivadas em instituições, ao mesmo tempo em que a subjetividade precisa encontrar formas para a sua expressão.

Análise similar vale para o conceito de "controle social" que não é menos ambíguo do que o de participação. Um breve relance sobre a literatura mostra compreensões muito distintas ao longo dos tempos e em contextos diferentes. Por exemplo, na literatura norte-americana é muito comum o uso de controle associado às teorias de desvio. É uma forma de "controlar" a delinqüência, a drogadição e outras formas de conduta que se desviam da normalidade. Na América Latina, diferentemente, controle social tende a ser associado com fiscalização. É a contrapartida da prestação de contas por parte do poder público.

A formação da palavra data do século $\mathrm{XV}$, sendo concomitante com a formação do capitalismo mercantil e do estado moderno e seu aparato fiscal. O termo é uma combinação anglo-francesa da contração contre-rolle, uma referência à duplicata de registros - financeiros e de propriedade - e que poderiam servir para fins de comparação e verificação. No século XVII, quando

5 Essas frases de um pensador chinês traduzem o que parecem ser traços importantes de um líder numa democracia participativa:

Um líder é melhor

Quando quase não se nota que ele existe,

Não tão bom quando as pessoas lhe obedecem e o aclamam,

Pior quando eles o detestam.

"Falte em honrar o povo,

e o povo vai faltar em honrar a ti;",

Mas de um bom líder, que fala pouco,

Quando seu trabalho estiver feito, seu objetivo realizado,

Todos vão dizer, "Nós mesmos realizamos isso."

(Lao Tzu, apud Bachrach e Botwinick, 1992, p. 42). 
se formularam as teorias mecanicistas do mundo, a idéia de controle passou a funcionar tanto para designar fenômenos sociais como físicos. Na Enciclopédia, no tempo que antecedeu a Revolução Francesa, controle era associado com a idéia de um funcionamento racional da sociedade, especialmente no aspecto jurídico. Para Adam Smith o controle encontrava-se no mecanismo abstrato do mercado como instância auto-reguladora.

Numa análise abrangente, Mirian R. Levin (2000, p. 21) identifica três características subjacentes ao discurso de controle: (a) controle tem a ver com técnicas e invenções que afetam a existência social psicológica ou física; ou seja, tem um caráter eminentemente tecnológico; (b) controle tem a ver com a circulação eficiente da energia, com processos de feedback, input, output etc.; (c) controle ainda tem a ver com a crença no poder da informação e comunicação para operar grandes e complexos sistemas. No campo social, a idéia de controle se funde com a crença iluminista de que é possível "controlar" os processos sociais para extender os benefícios sociais para todos os membros da sociedade.

Num estudo sociológico considerado fundante na área, Morris Janowitz (1975) conclui que embora os sociólogos tenham associado controle social com conformidade social e mesmo com repressão social, é importante voltar ao seu sentido clássico que o conectava a processos políticos e à crise de legitimidade política. Controle social, em sua origem, não era um conceito conservador nem se restringia à fiscalização. Correspondia à capacidade de a sociedade se auto-regular com vistas a determinado fim, sem o uso da força. Nesse sentido, controle social é o contrário de coerção social. Ainda segundo Janowitz, haveria compromissos de valor implícitos na idéia de controle social: (a) a redução da coecção através de um sistema de autoridade legítimo; (b) a eliminação da miséria humana como fim; (c) um compromisso com procedimentos para definir os objetivos socias de forma racional.

A análise acima possibilita alguns esclarecimentos no uso do conceito:

a) É inadequado equiparar controle social com fiscalização. O termo, numa compreensão mais abrangente, indica a co-responsabilidade em termos da coisa pública baseada numa relação de trabalho conjunto em vista a objetivos comuns. Esse alerta é sobretudo importante porque parece existir uma tendência de o poder público repartir a responsabilidade pelo não funcionamento de serviços ou pelo desvio de recursos com o público, num jogo que acaba culpabili- 
zando a própria vítima. A vigilância sobre a observação de regras e acordos faz parte desse processo, mas não o esgota, uma vez que controle social encerra também uma visão prospectiva, de formulação conjunta de metas e objetivos.

b) Controle social está relacionado com justiça social e nesse sentido se desdobra numa visão crítica sobre os fatores causadores da injustiça social. $\mathrm{O}$ conceito leva à pergunta pela legitimidade do aparato institucional e legal $\mathrm{e}$ não se limita a apontar irregularidades pontuais. Quando uma delegada do Orçamento Participativo confere se os funcionários de uma obra contratada fazem o seu serviço a contento ou se a bitola do cano na obra corresponde à do contrato do serviço estamos ainda diante de uma compreensão limitada de controle social. ${ }^{6} \mathrm{O}$ controle social implica numa compreensão abrangente da realidade e a respectiva possibilidade de encaminhamento de soluções para os problemas.

c) Controle social, como palavra-gêmea de participação, remete ao todo, ao funcionamento do sistema. É uma tarefa do sujeito coletivo que assume o desafio de trabalhar em conjunto, muito distante, portanto, do denuncismo interesseiro. Ao mesmo tempo, reconhece a conflitividade como parte necessária e importante do processo social. Pessoas e grupos têm interesses diferentes, muitas vezes contraditórios, e o controle social permite explicitar e encaminhar soluções que tenham como horizonte o bem comum.

\section{Lugares da participação}

A intenção nesta parte do estudo é mapear diferentes formas de participação e o seu papel dentro do que poderia ser chamado uma sociedade em movimento. Trata-se sobretudo de fornecer um quadro de referência para compreender a movimentação da sociedade e eventualmente descartar idéias simplistas, por exemplo, de que estamos diante de uma sociedade que não participa ou de que os jovens são politicamente alienados. ${ }^{7}$

6 Conforme depoimento numa Conferência Municipal das Cidades.

7 O mesmo estudo da América Latina que aponta para a superficialidade da democracia latinoamericana, indica também um amplo espectro de participação do cidadão e da cidadã na vida política e social de seus países. Apenas 7,3\% das pessoas consultadas não teria realizado nenhum ato de participação cidadão nos últimos anos, incluindo-se o voto. Quase quatro de dez $(37,6 \%)$ dos cidadãos latino-americanos participa de alguma atividade política para além das eleições, seja contactando as autoridades, envolvendo-se em manifestações públicas ou colaborando com recursos ou tempo para resolver problemas comuns (Pnud, 2004, p. 141). 
1. O voto: A Constituição Federal, além do sufrágio universal para eleição dos governantes e legisladores, no art. 14, garantiu a forma de consulta e iniciativa popular: "A soberania popular será exercida pelo sufrágio universal e pelo voto direto e secreto, com valor igual para todos, e, nos termos da lei, mediante: I - plebiscito; II - referendo; III - iniciativa popular". ${ }^{8}$ O plebiscito e o referendo são consultas formuladas ao povo para que delibere sobre questões importantes de natureza constitucional, legislativa ou administrativa. O plebiscito é a consulta anterior ao ato legislativo ou administrativo para que o povo, pelo voto popular delibere a favor ou contra a matéria submetida. Já o referendo é um encaminhamento posterior ao ato legislativo ou administrativo, para que o povo ratifique, ou não, determinada questão. A iniciativa popular é um direito constitucional que torna possível a um grupo de cidadãos e cidadãs apresentar projetos de lei para serem votados e, eventualmente, aprovados pelos deputados e senadores. O projeto de lei deve ser subscrito por, no mínimo, um por cento do eleitorado nacional (em torno de 950.000 eleitores), distribuído pelo menos por cinco estados, com um percentual não inferior a três décimos de por cento dos eleitores de cada um deles. Apesar dessas exigências, trata-se de um poderoso instrumento de exercício da cidadania, ainda pouco utilizado, ${ }^{9}$ porque permite a consagração de direitos também de forma legal.

2. Manifestações públicas: As manifetações públicas se caracterizam pelo seu caráter esporádico. Isso não significa, no entanto, que elas não sejam uma forma muito eficaz de participação. Vimos isso quando uma conjugação de movimentos sociais e de cidadãos bloqueou a conferência da Organização Mundial do Comércio (Genebra em 1998 e Seattle em 1999) ou quando a população se mobilizou para exigir o impedimento de Fernando Collor de Mello (dezembro de 1992) ou mais recentemente (2005) a saída do presidante equatoriano, Lúcio Gutiérrez.

8 O disposto nos incisos I, II, III desse art. da Constituição Federal foi regulamentado pela Lei $\mathrm{n}^{\circ}$ 9.709, de 18 de novembro de 1998.

9 Um exemplo é a Lei 9840 aprovada pelo Congresso Nacional em setembro de 1999, contra a corrupção eleitoral encaminhada por iniciativa da Comissão de Justiça e Paz da CNBB e outras organizações da sociedade. Da mesma forma o Projeto de Lei 2710/92 encaminhado pelo Fórum Nacional de Reforma Urbana foi finalmente aprovado no Senado após 14 anos de tramitação, cuja Lei correspondetne 11.124 foi sancionada em 16 de junho de 2005. A presente lei dispõe sobre o Sistema Nacional de Habitação de Interesse Social - SNHIS, cria o Fundo Nacional de Habitação de Interesse Social - FNHIS e institui o Conselho Gestor do FNHIS. 
O caráter emergencial e assistemático das manifestações pode ser visto, por um lado, como a expressão da vontade de ser partícipe direto na construção de seu destino. Por outro lado, as manifestações são também a expressão de que os anseios do povo não encontram canais de expressão e que as instâncias responsáveis pelas decisões precisam ser chamadas ao dialógo quando não substituídas.

3. Os movimentos sociais: Muitos princípios e métodos de participação e de organização democrática derivam da ação dos movimentos sociais. Alberto Melucci (1996, p. 28) identifica três características na ação coletiva que é denominada de movimento social: "Ela designa aquela forma de ação coletiva que (i) evoca solidariedade, (ii) torna explícito um conflito, e (iii) representa uma ruptura dos limites de compatibilidade do sistema dentro do qual a ação acontece."

Pelas três características acima elencadas pode-se avaliar a importância dos movimentos sociais para a saúde da democracia. São eles que empurram os limites do instituído, alargando o espaço do jogo político e abrindo novos canais de participação. A solidariedade interna é contrabalnçada com a conflitividade que introduzem no tecido social, geralmente em função de temas claramente delimitados: terra, moradia, direitos humanos, igualdade de gênero ou racial, entre outros.

Por exemplo, os movimentos sociais impulsionaram a criação do Orçamento Participativo em Porto Alegre, originando o que pode ser visto como um novo princípio ético político ao instituir uma relação entre o público e o privado na qual se rompe com a tutela do estado e se constrói um novo tipo de representação. $\mathrm{O}$ interesse da população deixa de estar apenas nos resultados imediados das políticas, mas se colocam em xeque o processo de produzir os resultados (Baierle, 2000, p. 212). O MST (Movimento dos Trabalhadores Rurais Sem Terra), através de ocupações e assentamentos, questiona a legimitidade da distribuição e do uso da terra e traz à consciência uma legalidade que instituiu e promoveu injustiças. O Movimento pela Reforma Urbana foi responsável pela introdução da questão urbana na Constituição Federal de 1988.

4. As associações: No Brasil e América Latina, algumas teorias de transição democrática subestimaram a organização autônoma da sociedade. Novas perspectivas teóricas de caráter culturalista começaram a valorizar as 
formas de ação social e abrem espaço para os movimentos sociais e associações da sociedade civil. Assim, as associações e movimentos sociais ampliam e incorporam novos temas na agenda política, desempenhando um papel fundamental na construção do espaço público estatal e não estatal (Liszt, 2005). A perspectiva republicanista tende a fundir o espaço público não estatal com o estado. Mas cada vez mais faz-se necessário reconhecer a autonomia e o papel do associativismo na esfera pública não-estatal. Em outras palavras, para reconhecer e valorizar as associações da sociedade civil como fundamentais para a democracia, exige-se que as mesmas não sejam absorvidas pelo espaço administrativo do estado.

Analisando o associativismo na cidade de São Paulo, pesquisadores (Avritzer, 2004, p. 19) construíram duas grandes categorias de associações: as religiosas e as civis. Entre as civis foram identificadas quatro subcategorias: (a) associações de caráter comunitário; (b) associações relacionadas com o mundo do trabalho; (c) associações voltadas para temas de cidadania e direitos humanos; (d) associações filantrópicas, culturais, grupos de jovens e de auto-ajuda. Diferentes contextos sociais com certeza apresentam diferentes configurações de tipos de associação, mas reconhece-se de modo geral o seu papel como formadores de um ethos de participação.

Nessa perspectiva, entendemos que há uma ruptura com o padrão homogeneizador de ação coletiva. Proliferam organizações não-governamentais e associações comunitárias que ocupam um espaço diferenciado e plural. Em função da cultura política, as organizações da sociedade civil são permeadas por contradições. Elas vivem, em geral, a tensão entre certa tendência ao corporativismo e a relação pública, tendo presente os interesses maiores do conjunto da sociedade. Como garantir uma mínima eqüidade, que não deixe de fora os setores desorganizados e contribua para privilegiar certos setores mais organizados?

5. As redes: Impulsionado pelo avanço das novas tecnologias de informação e comunicação surgiram nas últimas décadas incontáveis redes, "possibilitando processos capazes de responder às demandas de flexibilidade, conectividade e descentralização das esferas contemporâneas de atuação e articulação social" (Rede Rits - www.rits.org.br). 
Recentemente as associações e movimentos começaram a organizar a luta social em forma de redes. Estudos de Ilse Scherer-Warren (1993) dão conta de que se trata de uma organização social heterogênea e fragmentada, diferente do centralismo democrático das organizações tradicionais. Elas trazem importantes mudanças na sociabilidade e na espacialidade. Criam novos espaços de ação coletiva, novo imaginário social, ampliando, ao mesmo tempo, as possibilidades de comunicação virtual, mas excluindo setores que não têm acesso a esses meios informáticos. As redes se baseiam na solidariedade e coordenação horizontal e são práticas cujo potencial de ação coletiva precisa ainda ser melhor avaliado.

6. Os fóruns da sociedade civil: Nos últimos anos, multiplicaram-se os fóruns como estratégia de fortalecimento do poder político das organizações na busca da superação da fragmentação, do isolamento, do corporativismo. Sua constituição normalmente brota de uma proposta de articulação entre organizações, a partir de questões comuns, em torno de objetivos que podem ser coletivamente alcançados. Os fóruns são, portanto, espaços que reúnem pessoas representativas de organizações da sociedade civil para garantir direitos humanos, assegurar políticas sociais fundamentais. São instâncias de interesse público que partem do princípio de que as necessidades não são carências, mas a relação com um bem, com um serviço ou recurso existente. Os fóruns têm um formato e nível de institucionalização diversificado, podendo ou não ter uma estrutura jurídica. Propõem-se a questionar, formular políticas e realizar ações concretas. Exercem a mediação junto a interesses públicos, através do controle social sobre as instituições públicas ou privadas a eles relacionados.

Na prática os fóruns se constituem em espaços de articulação, de informação, discussão, formação e mobilização. Exercem pressão e controle social sobre as ações de governos ou mesmo instituições não governamentais. Constituem-se em espaços de apoio, retaguarda, subsídio, avaliação, qualificação e animação das entidades participantes e, ao mesmo tempo, contribuem na formação política para a defesa dos direitos e proposição de políticas emancipadoras.

Dentre os fóruns existentes, sobretudo no meio urbano, podem ser citados os do meio ambiente, do lixo e cidadania, fóruns de conselhos de políticas sociais, fóruns de entidades que atuam em determinado setor, fóruns de saúde, de educação, de mulheres, de economia solidária, de ONGs etc. 
7. Câmaras setoriais: Como uma espécie de conselho setorial instalaram-se, praticamente em todas as áreas da economia, mas também em torno da cultura, meio ambiente e outras questões, as chamadas câmaras setoriais. Com um caráter técnico, pretendem reunir determinados setores com o objetivo de ser uma estratégia de gestão em torno de cadeias produtivas e outras redes, como fóruns de apoio, de proposição e acompanhamento das ações para o desenvolvimento das atividades de cada setor. O próprio Conselho das Cidades é composto por quatro Câmaras Setoriais: Habitação, Planejamento Territorial Urbano, Saneamento Ambiental e Transporte e Mobilidade Urbana, do qual fazem parte os titulares, suplentes, observadores e membros indicados.

8. A gestão participativa: Os limites da democracia representativa estão provocando, em todo o mundo, a busca da participação direta de cidadãos na gestão da coisa pública. $\mathrm{O}$ voto em períodos eleitorais se tornou insuficiente tanto para o cidadão quanto aos responsáveis pela gestão. $O$ primeiro não se sente suficientemente representado num contexto de rápidas mudanças e o segundo não encontra canais eficazes para saber se suas ações ou políticas correspondem às necessidades da população.

Nesse contexto surgem as iniciativas de participação direta do cidadão na gestão e que assume formas muito distintas de acordo com o nível de participação proposto e com as condições sociais, políticas e econômicas da região. A experiência mais radical é, sem dúvida, o Orçamento Participativo pelo fato de haver propiciado um envolvimento em torno da aplicação dos recursos, um fator decisivo na realização das políticas públicas. Estima-se que existem no Brasil 103 municípios (Avritzer e Navarro, 2003, p. 13), sob a gestão de diferentes partidos, que executam o Orçamento Participativo. Os formatos são diferentes, mas todos eles correspondem a uma necessidade sentida, em ambos os lados, de romper a distância entre governantes e governados.

9. As conferências. Intrinsecamente ligado com o processo dos Conselhos estão as conferências, igualmente previstas em leis orgânicas e que acontecem na esfera municipal, estadual e nacional. Têm a finalidade de discutir e deliberar com ampla participação da população as diretrizes e estratégias das políticas a serem implementadas pelos gestores nas referidas políticas públicas. São espaços de referência também para os Conselhos que vão embasar seus planos de ação inspirados nas diretrizes políticas definidas pelas Conferências. 
10. Os conselhos: Os conselhos constituem uma forma híbrida de participação, situando-se, por um lado, no contexto das instituições oficiais e, por outro, mantendo a possibilidade de forte vinculação com as bases da sociedade que representam em determinado tema ou segmento social. Dada a sua peculiaridade, complexidade e importância no contexto deste estudo, será dedicado um item especial aos conselhos.

Uma avaliação da participação, hoje, precisa dar conta da multiplicidade de canais através dos quais as pessoas se manifestam e constróem as suas identidades pessoas e coletivas. Sem essa visão de conjunto, corre-se o risco de perpetuar o distanciamento entre governo e governados, entre representantes e (supostamente) representados. Especialmente os conselhos, dada a sua função articuladora, devem dar atenção a este complexo cruzamento de canais de participação para não se tornarem mais uma vez estruturas vazias, meras cumpridoras de formalidades.

\section{Os conselhos: um campo de disputas e possibilidades}

Os conselhos gestores ou de políticas públicas são reconhecidos como uma conquista da sociedade organizada na luta pela redemocratização no decorrer das décadas de 1970 e 1980 . Com o processo de democratização do estado, novos formatos e atores foram sendo incorporados, sendo que os conselhos resultam como instrumentos centrais no processo de reestruturação e legitimação de políticas afirmadas pelos novos princípios constitucionais. “A constituição e participação em conselhos poderia significar um momento de organização e de direção das lutas políticas dispersas e fragmentadas" (Gohn, 2001, p. 75). Tendo iniciado sua instituição no âmbito federal, os conselhos passam a ser obrigatórios nas três esferas estatais vinculados ao repasse de recursos do governo federal para os governos estaduais e municipais.

A sua consolidação, frente a possibilidades e limites da maior participação e controle social, situa-se no campo contraditório de disputas e negociação de conflitos. Com o processo de institucionalização de espaços de participação sempre há perdas e ganhos, riscos e possibilidades que são próprias de duas lógicas e tempos diferentes: a dos movimentos sociais e dos gestores do estado. 
Contudo, apesar das contradições, os conselhos gestores foram a grande novidade na gestão das políticas sociais. Com caráter interinstitucional, eles têm o papel de instrumento mediador na relação sociedade/estado, como canais de um novo regime de ação pública (Gohn, 2001; Santos Junior, 2005).

Os conselhos podem ser compreendidos de acordo com suas característi$\operatorname{cas}^{10}$ e campos de atuação:

a) Conselhos gestores de programas governamentais como merenda ou alimentação escolar, ensino fundamental etc.

b) Conselhos de políticas setoriais, por meio da elaboração, implantação e controle das políticas públicas definidas por leis federais;

c) Conselhos temáticos, que visam acompanhar ações governamentais junto a temas transversais relacionados a direitos humanos, violência, discriminação contra a mulher, contra o negro e outras questões;

d) Conselhos com temáticas mais amplas como os de Desenvolvimento Municipal, de Desenvolvimento Urbano, Desenvolvimento Regional e outros.

Há alguns conselhos que se relacionam diretamente à chamada questão urbana como o ambiente, a moradia (Conselho das Cidades). Outros situam-se em espaços decorrentes da prestação de serviços urbanos por setores da administração: saúde, educação, transporte etc. Um terceiro grupo de conselhos assume as políticas focalizadas em grupos etários da população: idosos, crianças e adolescentes; ou também categorias específicas como mulheres, negros, índios, sempre voltados aos problemas que interferem na qualidade de vida do meio urbano. E há um quarto grupo de conselhos que se situa na área da cultura que na perspectiva da humanização do espaço humano é essencial e deve perpassar todas as políticas públicas. A qualidade de vida passa pela satisfação das necessidades biológicas/materiais, relacionadas com as necessidades da convivência humana/(necessidades imateriais/espirituais): dimensão da cultura, da educação, da espiritualidade, do lazer, da convivência solidária/comunitária, da festa, entre outras.

10 Santos Junior (2004, p. 2-3) identifica os conselhos como: temáticos, de caráter semirepresentativo, deliberativos abrangentes e permanentes, de composição paritária, com autonomia ou semi-autonomia em relação aos governos. 
Quanto ao caráter e poder decisório, os conselhos podem ter a finalidade de deliberação, consulta e controle social.

Os conselhos assumem sua atribuição deliberativa quando definem e aprovam proposta orçamentária, diretrizes, transferência de recursos financeiros, critérios e valores para remuneração de serviços e sua programação. Também são deliberativos quando convocam extraordinariamente conferências para efetuar avaliações e formulações da política setorial, criar comissões permanentes ou provisórias e outras atribuições.

Os conselhos assumem sua atribuição em caráter consultivo através de recomendações ou moções sobre determinadas questões relacionadas direta ou indiretamente com a referida política. Trata-se de manifestações decorrentes de posicionamentos do conselho definido em plenária, mas cujo mérito ultrapassa o poder do conselho. Exemplos dessas ações são o acompanhamento do gestor responsável no processo de planejamento, a proposição de critérios para a definição de padrões e parâmetros assistenciais; o acompanhamento à observação de critérios éticos na atuação dos profissionais da área na relação com os usuários.

Os conselhos exercem controle quando discutem sobre a movimentação e transferência dos recursos financeiros, bem como na execução da política no âmbito da sua área de atuação, acompanhando e controlando os fundos e a implementação dos planos de gestão.

Em tese, os conselhos gestores são novos instrumentos de expressão, representação e participação, com potencial de transformação política. Se eles forem de fato representativos podem consolidar uma nova prática de gestão no âmbito das políticas sociais. Inauguram um novo padrão de relações entre estado e sociedade, gerando uma nova institucionalidade pública e viabilizando o acesso da população à formulação de políticas. Mas terão os conselhos condições de reaglutinar os direitos fragmentados frente às políticas desconstrutoras do sentido público como tem acontecido na lógica do estado no modelo neoliberal?

Em muitos casos, os conselhos foram criados pelo Poder Executivo apenas em função da condição que a legislação federal preconiza desde 1996, para que os municípios possam acessar os recursos financeiros. A existência jurídicoformal, por si mesma, não contribui na mudança da cultura política e na ampliação da participação cidadã. Mas, mesmo nos casos de práticas não democráticas, através do princípio da contradição, é possível valorizar os conselhos pelo seu potencial participativo. 


\section{Perspectivas e desafios}

A participação e o controle social se dão em condições históricas e sociais concretas que, se não levadas em conta, conduzem a visões demasiadamente fragmentadas e parciais da cidadania. O movimento da sociedade através dos diversos lugares onde se dá a participação mostra que temos, no Brasil, um acúmulo de experiências capazes de alavancar a atividade política - no seu sentido nobre de cuidado da polis como espaço público de organização e fruição da vida - ao nível que este país está por merecer.

Dentre os muitos lugares, neste momento cabe uma atenção especial aos conselhos. A efetivação crescente de conselhos em todas as áreas sociais e temáticas, nos três níveis da federação, contabiliza muitos ganhos visivelmente percebidos e, de alguma forma, também indicados neste estudo. Contudo, para que possam efetivamente contribuir no fortalecimento da sociedade civil na perspectiva agregadora da construção do público será necessário enfrentar alguns desafios, tensões e até mesmo contradições.

Os conselhos, na sua concepção e ação, carregam a tensão entre uma visão que parte dos setores liberais e outra oriunda de setores identificados com as lutas e práticas políticas dos movimentos sociais populares. Os primeiros os consideram instrumentos de colaboração na implantação de políticas. A segunda concepção investe na perspectiva de agregar esse espaço para fortalecer as possibilidades de mudanças sociais, de democratização das relações de poder na sociedade. Assim, os conselhos podem ser instrumentos valiosos para avançar na gestão democrática e participativa, afirmando uma relação mais interativa entre governo e sociedade em torno das políticas sociais. Em outras palavras, possibilitam um processo de participação sociopolítica de grupos organizados, podendo contribuir para alterar a natureza do poder local. Mas poderão também limitar-se a estruturas burocráticas, formais e de desvirtuamento das responsabilidades dos governos na relação com a sociedade. Em vez de espaços construtores de cidadania e autonomia podem ser utilizados como espaços de manipulação.

Embora carreguem a contradição como qualquer espaço institucional, acreditamos ser possível, de forma articulada com outros movimentos da sociedade, tornar os conselhos atuantes, fiscalizadores das ações do poder 
público e participantes da construção das bases de uma gestão mais democrática. Pelo fato de os conselhos se situarem nas esferas do consumo, da distribuição de bens, serviços e equipamentos públicos, e pelo fato de atuarem na esfera da produção de bens essenciais à vida carregam um potencial estratégico que não pode ser abandonado em função das dificuldades concretas de sua efetivação.

Os lugares de participação são também - e quem sabe sobretudo - espaços de aprendizagem da cidadania. As aprendizagens numa rede são distintas daquelas de uma manifestação pública ou de um movimento social, mas elas interagem como expressões de um povo que quer dizer a sua palavra e ser ouvido, condições essenciais para a construção de uma esfera pública saudável.

\section{Referências}

AVRITZER, Leonardo (org.). A participação em São Paulo. São Paulo: Editora Unesp, 2004.

AVRITZER, Leonardo; NAVARRO, Zander (orgs.). A inovação democrática no Brasil: o orçamento participativo. São Paulo: Cortez, 2003.

BAIERLE, Sérgio Gregório. A explosão da experiência. Emergência de um novo princípio ético-político nos movimentos populares urbanos em Porto Alegre. In: ALVAREZ, Sonia E.; DAGNINO, Evelina; ESCOBAR, Arturo (orgs.). Cultura e politica nos movimentos sociais latino-americanos: novas leituras. Belo Horizonte: Editora Ufmg, 2000, p. 185-220.

BACHRACH, Peter; BOTWINICK, Aryeh. Power and empowerment. Philadelphia: Temple University Press, 1992.

BENELLO, C. George; ROUSSOPOULOS, Dimitrios (orgs.). The case for participatory democracy: some prospects for a radical society. New York: Grossmann Punlishers, 1971.

BAQUERO, Marcelo. A vulnerabilidade dos partidos politicos e a crise da democracia na América Latina. Porto Alegre: Ed. Universidade/Ufrgs, 2000.

BOFF, Leonardo. A voz do arco-íris. Brasília: Letraviva, 2000.

BONAMUSA, Margarita. Que es la sociedad civil? Una mirada a Colombia. In: LONDOÑO, L. F. et al. Sociedad civil, control social y democracia participativa. Bogotá: Tercer Mundo Editores, 1997, p. 65-88. 
GOHN, Maria da Glória. Conselhos gestores e participação sociopolítica. São Paulo: Cortez, 2001.

FEDOZZI, Luciano. Orçamento Participativo: reflexões sobre a experiência de Porto Alegre. Porto Alegre: Tomo, 1999.

JANOWITZ, Morris. Sociological theory and social control. American Journal of sociology. v. 81, n. 1. p. 82-108.

JONES, Gareth A. The geopolitics of democracy and citizenship in Latin America. In: BARNETT, Clive; LOW, Murray M. Geographical perspectives on citizenship, participation and representation. London: Sage Publications, 2004, p. 161-184.

LEVIN, Miriam R. Cultures of control. Amsterdam: Harwood Academic Publishers, 2000.

LONDOÑO, Juan Fernando et al. Sociedad civil, control social y democracia participativa. Bogotá: Tercer Mundo Editores, 1997.

MELUCCI, Alberto. Challenging codes: collective action in the information age. Cambridge: Cambridge University Press, 1996.

MINISTÉRIO DAS CIDADES. Participação e controle social. Cadernos Mcidades, 2004.

OPPENHEIMER, Martin. The limitations of Socialism: some sociological observations on participatory democracy. In: BENELLO, George; ROUSSOPOULOS, Dimitrios (orgs.). The case for participatory democracy: some prospects for a radical society. New York: Grossman Publishers, 1971, p. 271-282.

PATEMAN, Carole. Participação e teoria democrática. Trad. Luiz Paulo Rouanet. Rio de Janeiro: Paz e Terra, 1992.

PROGRAMA CIUDADANÍA Y GESTIÓN LOCAL. Los caminos que buscamos: 30 innovaciones en el fortalecimiento del espacio público local. Universidad de Chile: Centro de Análisis de Políticas Públicas, 2000, p. 12-56.

RESTREPO, Luis Alberto. La participación ciudadana: participación tutelada o participación abierta? In: LONDOÑO, L. F. et al. Sociedad civil, control social y democracia participativa. Bogotá: Tercer Mundo Editores, 1997, p. 27-38.

SANTOS, Boaventura de Sousa. Democratizar a democracia: os caminhos da democracia participativa. 2. ed. Rio de Janeiro: Civilização Brasileira, 2003.

SANTOS JUNIOR, Orlando Alves dos. Reforma urbana e gestão democrática: um ano de funcionamento do Conselho das Cidades. Fase, 2005.

STEWART, John. Democracy and local government. In: HIRST, Paul; KHILNANI, Sunil (orgs.). Reinventing democracy. Cambridge: The Political Quarterly Publishing, 1996, p. 39-56. 
STRECK, Danilo R. Educação para um novo contrato social. Petrópolis: Vozes, 2003.

TATAGIBA, Luciana. A institucionalização da participação: os conselhos municipais de políticas públicas na cidade de São Paulo. In: AVRITZER, Leonardo (org.). A participação em São Paulo. São Paulo: Unesp, 2004, p. 323-370.

VIEIRA, Liszt. Cidadania e sociedade civil no espaço público democrático. Disponível em:

$<$ http://www.puc-rio.br/sobrepuc/depto/direito/revista/online/rev11_liszt.html $>$.

Acessado em: 9 mar. 2006.

WRIGHT, Tony. Reinventing democracy? In: HIRST, Paul; KHILNANI, Sunil (orgs.). Reinventing democracy. Cambridge: The Political Quarterly Publishing, 1996, p. 7-19.

Recebido em 16 de novembro de 2005 e aprovado em 4 de fevereiro de 2006 